\title{
Usage of antifungal drugs for therapy of genital Candida infections, purchased as over-the-counter products or by prescription: 2. Factors that may have influenced the marked changes in sales volumes during the 1990s
}

\author{
Per-Anders Mårdh ${ }^{1}$, Jolanta Wågström², Maria Landgren ${ }^{2}$ and Jan Holmén ${ }^{3}$ \\ ${ }^{1}$ Department of Obstetrics and Gynaecology, University Hospital, Lund, \\ ${ }^{2}$ Apoteket $A B$ (The National Corporation of Swedish Pharmacies), and \\ ${ }^{3}$ Informationscentrum Skåne, Hospital Pharmacy, Varberg, Sweden
}

Background: The epidemiology of vulvovaginal candidiasis (VC) and such recurrent infections (RVVC) has been difficult to study as the majority of episodes of these conditions are self-treated by the women affected. In Sweden, all pharmacies are owned by the state and all prescriptions and over-the-counter (OTC) products, such as antifungals, are registered in a database, which offers unique possibilities to study the epidemiology of WC/RVVC.

Objectives: To analyze all prescriptions and OTC products purchased for therapy of WVC/RVC and to establish reasons for any observed variation in the sales figures.

Methods: Sales figures in the Swedish county of Skåne of antifungal drugs for therapy of WVCRVVC were analyzed by the aid of the 'ACS' database of the National Corporation of Swedish Pharmacies for the years 1990-1999. The size of the female population in the county is approximately half a million.

Results: The study showed that $93 \%$ of all antifungal drugs for WVC/RVVC were sold as OTC products. An increase in sales of the drugs occurred until mid-1993/94, followed by a decrease until end of the study period in 1999. Demographic factors (e.g. the number of female inhabitants in the county, pharmacies and health-care units), the pregnancy rate and pharmacy-dependent factors (such as the introduction of shelves for selfselection of antifungal products) did not explain the observed variations in sales. Distinct short-term variations in the number of prescriptions of fluconazole and itraconazole could be explained by drugs company sales campaigns and logistics factors in drug distribution. The sales volumes in the 33 municipalities in the county correlated with the density of the population, which was not the case for the total number of prescriptions made in the county during the 1990s. The variation in antifungal drug sales was similar to that of hormonal intrauterine devices, but this was not the case for oral contraceptives. The total Swedish usage of antibiotics showed a similar variation to that of the antifungal drugs analyzed.

Conclusion: The study stresses the limited impact on the treatment of WVC/RVVC by the medical community. Behavior-related factors in the female population are the most likely explanation for the marked variations found in the usage of drugs for the two conditions.

Key words: Antifungals Sales Volumes; Prescriptions of ANTi-CANDida Drugs; Over-THECounter Azole Products; Epidemiology of VVC AND RVVC

Correspondence to: Per-Anders Mårdh, MD, Department of Obstetrics and Gynaecology, University Hospital, SE-221 85 Lund, Sweden. E-mail: per-anders.mardh@gyn.lu.se 
Genital Candida infections, i.e. vulvovaginal candidiasis (VVC), and such recurrent infections (RVVC) are common conditions ${ }^{1-3}$. The diagnosis of RVVC, if based only on history and clinical examination, is frequently wrong ${ }^{4-7}$. The majority of assumed episodes of VVC and RVVC are treated by the women themselves, without involvement of any health-care providers. Studies of the epidemiology of these conditions are therefore difficult to perform by conventional means, such as the surveillance of cases seen by health-care providers. However, analyses of the usage of antifungal drugs aimed for therapy of these conditions may be one way to overcome this dilemma.

To explain changes over time in sales volumes of drugs for therapy of VVC/RVVC, not only pharmacy-related factors (e.g. the number of pharmacies in the area, the introduction of shelves for self-selection of over-the-counter (OTC) products and counseling activities) have to be analyzed. Other factors that have to be considered are any demographic alterations, such as changes in the size of age groups of women particularly susceptible to genital Candida infections, and also the number of pregnancies, because pregnant women are more commonly affected by genital Candida infections. Changes in health insurance systems, i.e. in drug subsidies, are other accountable factors to be considered. Furthermore, sales promotion activities by drug companies may have an influence on sales volumes of any drug (Table 1).

The present study is an extension of a previous study $^{8}$, where we reported the sales pattern of antifungal drugs that are almost exclusively used for therapy of VVC and RVVC. In this second paper, we have analyzed a number of factors that might have had an influence on the fluctuations noted in the usage of such drugs, sold either as prescriptions or as OTC products, in a Swedish county (with approximately 1 million inhabitants) during the 1990s.

\section{MATERIALS AND METHODS}

\section{Database and analyses performed}

The drugs that were available in Sweden for the treatment of VVC/RVVC during the 1990s are shown in Table 2. Sales data for these drugs and the packages analyzed (which are used more or less exclusively for therapy of genital Candida infections in females), from all pharmacies in the Swedish county of Skåne during the period January 1990 to the end of November 1999, were reported in the earlier study ${ }^{8}$. The data analyzed were derived from Apoteket AB's 'ACS' database'. Thus, we analyzed all packages sold for vaginal application and all packages with one capsule of $150 \mathrm{mg}$ fluconazole or with four capsules of $100 \mathrm{mg}$ itraconazole for oral intake, i.e. packages also almost exclusively used for therapy of VVC/RVVC. We chose to analyze the number of packages sold, instead of Defined Daily Dose, as we wanted to study the sales of drugs particularly used to treat VVC/RVVC. All drugs sales are registered in the ACS database, but in contrast to prescribed drugs, OTC product sales cannot be analyzed as to sex and age of the consumer (because such data are not requested from the customer). It should be noted that only the state-owned pharmacies in Sweden are allowed to sell antifungal drugs.

In the present study, we report for the first time on the specific sales figures for azole drugs for Kristianstad county (Table 3), which, together with the former Malmöhus county, now makes up the county of Skåne in southern Sweden. However, the discussion presented here refers to the situation in the new, current county of Skåne with its former two parts.

\section{RESULTS AND DISCUSSION}

\section{Type of drugs available during the study period}

The drugs most commonly used in the management of VVC and RVVC belong to the group of azole compounds ${ }^{10-12}$. The azoles used for vaginal application in Skåne, during the whole or part of the study period, were clotrimazole $\left(\right.$ Canesten ${ }^{\mathbb{R}}$ ), econazole (Pevaryl ${ }^{\mathbb{R}}$ ) and miconazole $\left(\right.$ Daktar $\left.^{(\mathbb{R}}\right)$ (Table 2). Econazole held twothirds of the market. Fluconazole (Diflucan ${ }^{\mathbb{B}}$ ) and itraconazole (Sporanox ${ }^{\mathbb{R}}$ ) were used for general therapy of VVC/RVVC and held more than 90\% of the market of oral drugs for anti-Candida therapy. 
Table I Factors that may influence usage of antifungal drugs in an area over time, with special reference to Candida infections of the genital tract

\begin{tabular}{|c|c|}
\hline Demographic & $\begin{array}{l}\text { No. of persons in the area who are particularly susceptible to genital fungal } \\
\text { infections, i.e. age distribution of the population } \\
\text { No. of pregnancies per study period }\end{array}$ \\
\hline $\begin{array}{l}\text { Health-care providers } \\
\text { and clients }\end{array}$ & $\begin{array}{l}\text { No. of doctors and midwives (prescribing or recommending antifungal drug use) in the area } \\
\text { No. of gynaecological and youth clinics in the area } \\
\text { No. of women assumed by health providers to be affected by WV/RVC } \\
\text { Women assuming themselves to be infected by Candida } \\
\text { Health-seeking behavior of affected women }\end{array}$ \\
\hline Economy & $\begin{array}{l}\text { Patient's private economy } \\
\text { Allocation of society resources to health care } \\
\text { Provision of drug cost by general or private health insurance programs }\end{array}$ \\
\hline Area epidemiology & $\begin{array}{l}\text { No. of persons with WVC and RVVC } \\
\text { No. of HIV-infected persons } \\
\text { No. of women with bacterial vaginosis } \\
\text { No. of individuals with uncontrolled diabetes } \\
\text { No. of immunocompromised patients } \\
\text { No. of cases in intensive care }\end{array}$ \\
\hline Pharmacy-dependent & $\begin{array}{l}\text { No. of pharmacies displaying OTC products for self-service } \\
\text { Counseling activities at pharmacies } \\
\text { Price of drugs }\end{array}$ \\
\hline Drug company initiatives & $\begin{array}{l}\text { Information campaigns by visits to pharmacies and physicians } \\
\text { Advertising directed to prescribers } \\
\text { Advertising of OTC products directed to the general population }\end{array}$ \\
\hline $\begin{array}{l}\text { Use of drugs and other } \\
\text { products }\end{array}$ & $\begin{array}{l}\text { Intimate hygiene products } \\
\text { Oral contraceptives } \\
\text { Hormonal IUDs }\end{array}$ \\
\hline Sexuality & $\begin{array}{l}\text { Age of sexual debut } \\
\text { Frequency of partner changes } \\
\text { Sexual practice }\end{array}$ \\
\hline Clothing & $\begin{array}{l}\text { Synthetic materials in underwear } \\
\text { Tight-fitting garments }\end{array}$ \\
\hline
\end{tabular}

WC, vulvovaginal candidiasis; RVVC, recurrent VVC; HIV, human immunodeficiency virus; OTC, over-the-counter; IUD, intrauterine device

\section{Choice of azole drugs by prescribers and by women for self-treatment}

The packages of Pevaryl Depot ${ }^{\circledR}$, Pevaryl and Canesten (all aimed for vaginal use) sold OTC in the five administrative health districts in Skåne county during January-December 1999 are shown in Figure 1. The figures refer to the sales volumes in the five different districts, per 1000 female inhabitants $15-45$ years of age. The relative proportions of these products purchased were similar in the five districts. This indicates that there was no difference in local pharmacy/ drug prescriber's policies or in consumer usage habits with regard to selection of the different OTC azole products available.

\section{Demographic factors}

The size of the consumer group most likely to use drugs for VVC/RVVC therapy, i.e. women of childbearing age, is one of the factors that can influence sales figures of antifungal drugs. However, the female population in Skåne county remained unchanged during the study period (Figure 2). This was also true for the age distribution of the female inhabitants. Thus, this demographic factor is not likely to explain the 
Table 2 Antifungal drugs, used mainly for therapy of genital Candida infections in women, that were available in Swedish pharmacies during the 1990s

Clotrimazole (Canesten ${ }^{\mathrm{R}}$ ) $1 \%$ and 10\% vaginal cream, pessaries at 100, 200 and $500 \mathrm{mg}$, and combination package with 300 or $500 \mathrm{mg}$ pessaries and $1 \%$ cream

Econazole $\left(\right.$ Pevaryl ${ }^{\mathbb{R}}$ ) $1 \%$ vaginal cream, pessaries at 50 and $150 \mathrm{mg}$, and combination package with $150 \mathrm{mg}$ pessaries and $1 \%$ cream. Econazole was also available as Pevaryl Depot ${ }^{\mathbb{R}}$ as pessaries of $150 \mathrm{mg}$ and in a combination package with such pessaries and $1 \%$ cream

Miconazole $\left(\right.$ Daktar $\left.^{\mathbb{R}}\right) 2 \%$ vaginal cream and pessaries at $150 \mathrm{mg}$

Fluconazole (Diflucan ${ }^{\circledR}$ ) $150 \mathrm{mg}$ capsules

Itraconazole (Sporanox ${ }^{\mathbb{R}}$ ) 100 mg capsules

Table 3 Sales in Kristianstad county, Sweden, of three azole drugs used more or less exclusively for therapy of vulvovaginal candidiasis and such recurrent infections for the period January 1990 to November 1999

\begin{tabular}{lccc}
\hline & \multicolumn{3}{c}{ Drug } \\
\cline { 2 - 4 } Year & $A$ & $B$ & $C$ \\
\hline 1990 & 19633 & 7337 & 18008 \\
1991 & 19926 & 6605 & 22924 \\
1992 & 20036 & 5932 & 26116 \\
1993 & 12803 & 4321 & 45229 \\
1994 & 12524 & 3555 & 53432 \\
1996 & 14833 & 2662 & 47860 \\
1997 & 13204 & 2027 & 44667 \\
1998 & 12933 & 1869 & 43465 \\
1999 & 11221 & 1573 & 40459 \\
\hline
\end{tabular}

observed change in usage pattern of the drugs studied. As pregnancy is associated with an increased rate of VVC/RVVC episodes, changes in the number of pregnant women during the study period is another factor that can alter the usage pattern. The deliveries in Skåne county showed a continuous decrease during the 1990s (with some minor deviations from the trend for two separate years), i.e. from 14677 deliveries in 1990 to 8241 in 1999. Thus, neither is this factor likely to explain the changes in sales volumes over the study period.

\section{Usage of antifungal drugs in rural and urban areas}

The number of prescriptions of fluconazole and itraconazole in relation to the number of women aged 15-55 years in 1999, in the 33 different municipalities in Skåne county, are illustrated in Figure 3a. The various municipalities in the county showed great variation in the sales figures for these drugs, even after adjustment for the age of their populations. In comparison, the sales of all medical drugs to women aged $15-45$ years in the municipalities did not show any such trend (Figure $3 \mathrm{~b})$. That is, usage of medical drugs, in general, was not higher in the mainly urban than in the mainly rural areas of the county. The variations in sales volumes of antifungal drugs that are available only by prescription could not be explained by differences in the ease with which potential customers accessed to health-care units. Healthseeking behavior of urban and rural populations may also differ; inhabitants in the former areas may more often consult for problems considered less serious, like genital Candida infections.

Differences between the various geographic areas in Skåne county with respect to the number of immigrants and second-generation immigrants might have contributed to some of the differences observed in the usage pattern of antifungal drugs between the various municipalities (with most sales in the most densely populated areas), because pregnancies are more common in these groups than among other inhabitants in Skåne county. Most immigrants live in the most densely populated municipalities in Skåne such as Malmö city, which is the largest city in the county and where approximately one-third of all children are born to women with an immigrant background.

\section{Pharmacy-dependent issues and drug subsidies}

The Swedish pharmacies are all state-owned and are the only commercial source of antifungal 


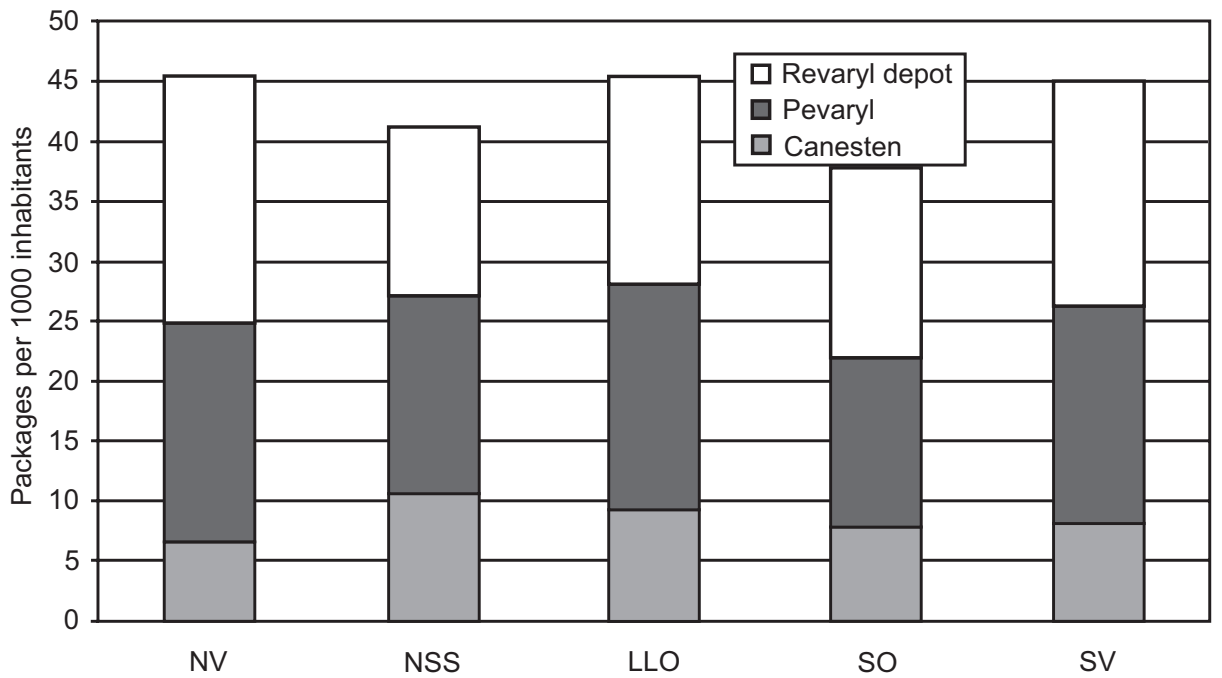

Figure I Sales volumes in 1999 of azoles prescribed per 1000 female inhabitants in the five administrative health units in the county of Skåne, Sweden

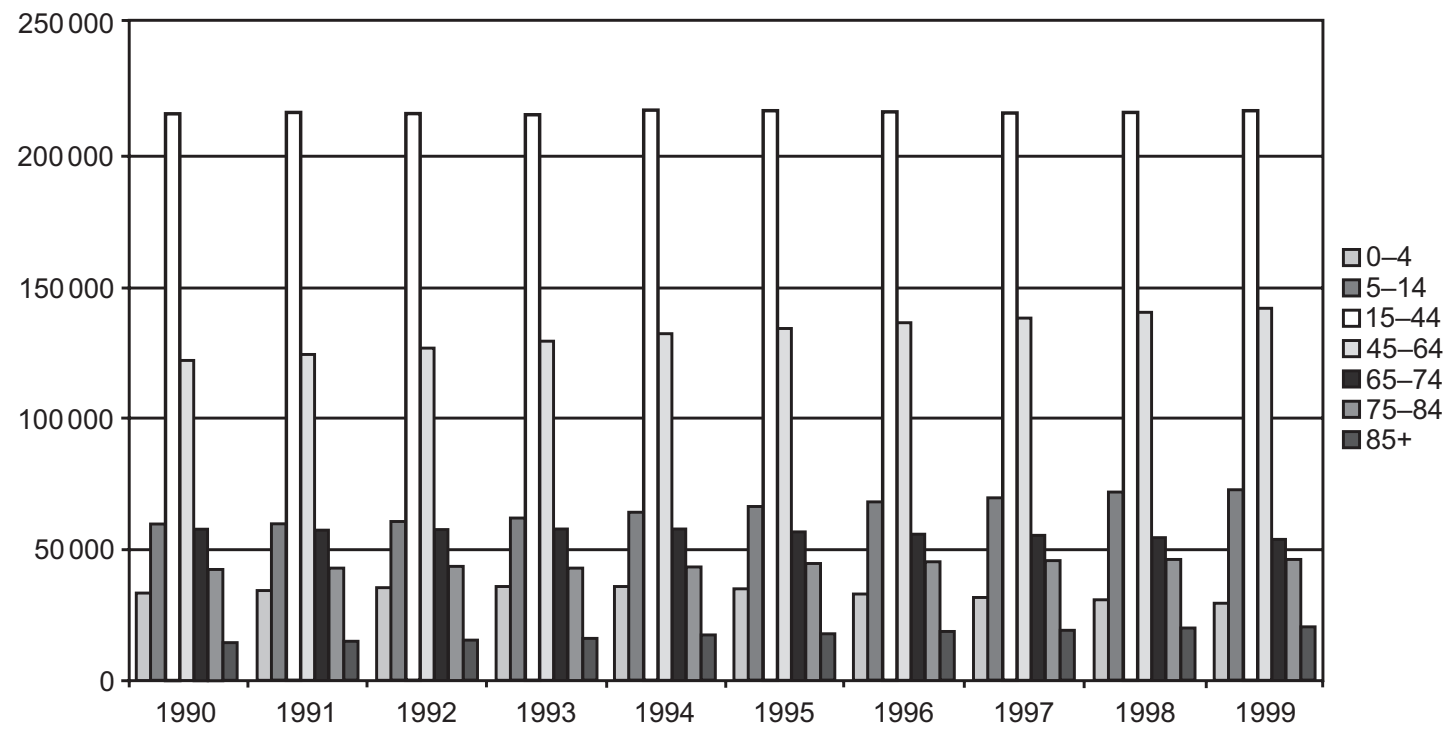

Figure 2 Age distribution of the female population of Skåne county, Sweden, 1990-1999

drugs. The number of pharmacies in Skåne county remained the same throughout the 1990s, at approximately 100 . The pharmacies in Skåne displaying OTC products for customers remained unchanged during this period. This was also true for counseling activities for antifungal OTC products (Landgren and colleagues, unpublished data).

Sales promotion activities for drugs for VVC/ RVVC therapy, appealing directly to potential groups of female consumers, was allowed by Swedish health authorities during the study period, e.g. by advertisements in the tabloid press for female readers. 'Drug committees' run by local health authorities could have had an impact on sales figures only for prescriptions, not for the bulk of products used for these indications, as they were sold OTC.

During the 1990s, there were a number of changes to medical drug subsidies nationally in 
(a)

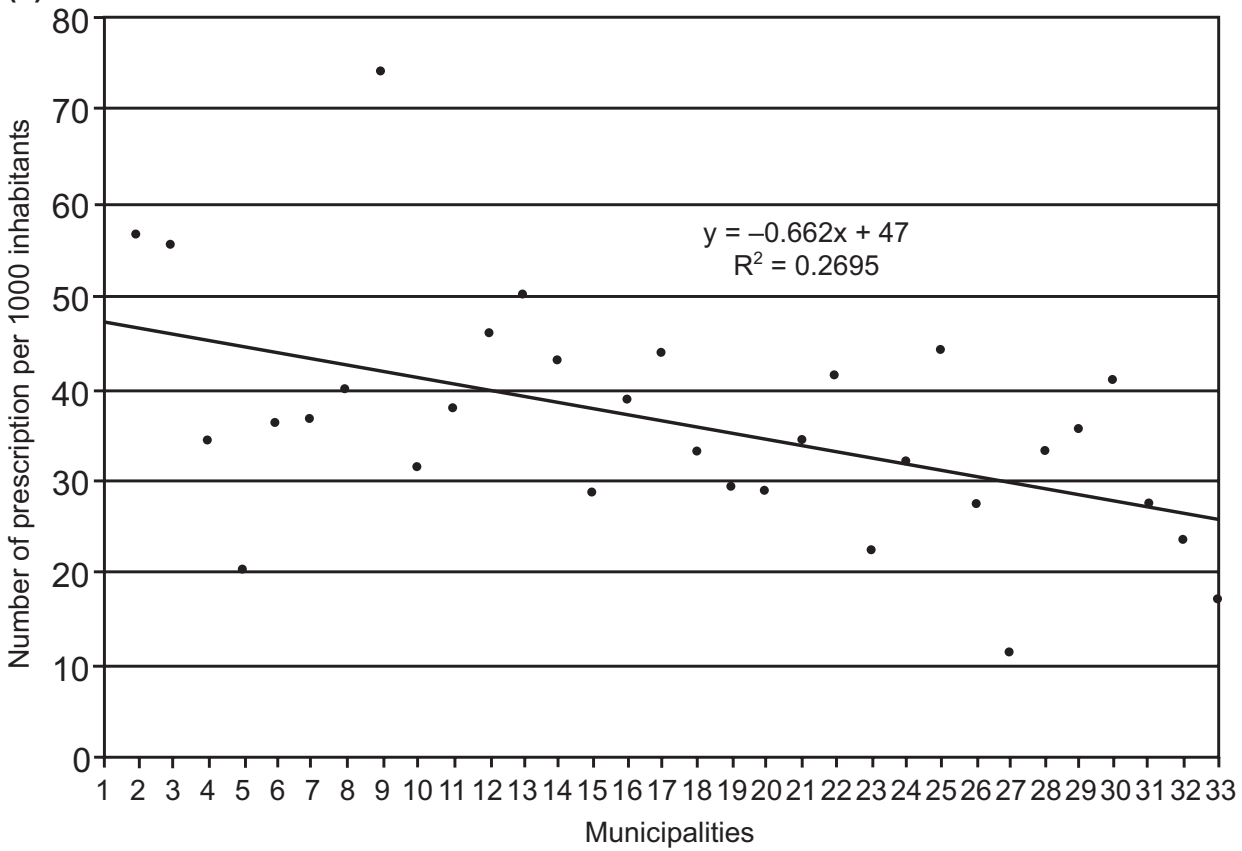

(b)

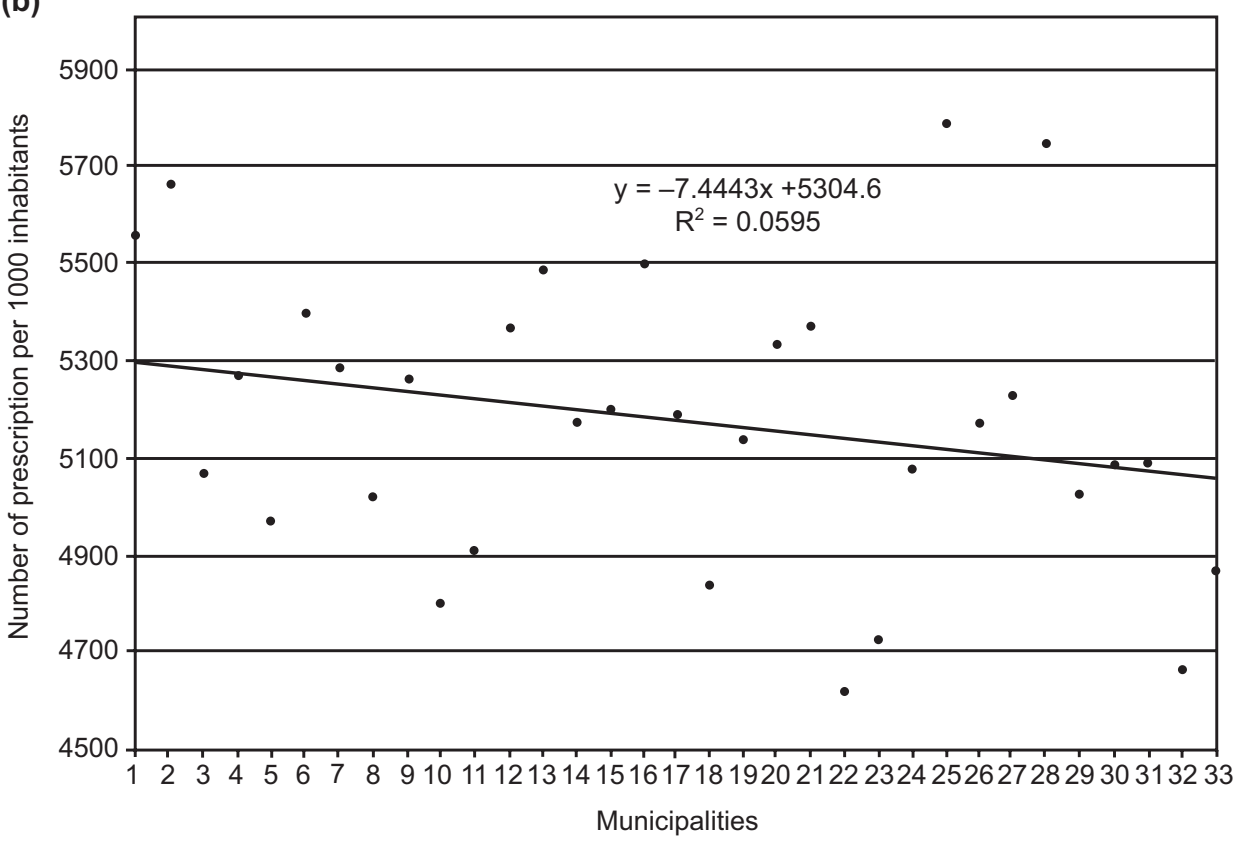

Figure 3 Correlation between density of the female population aged 15-50 years in 1999 in the 33 municipalities in Skåne county, Sweden, and the usage of (a) fluconazole and itraconazole and (b) all medical drugs sold by prescription in the municipalities during that time. Municipalities are ranked from left to right in the order of most inhabitants. Data are age-standardized

Sweden. Before 1997, a fixed maximum sum had to be paid for all prescriptions made for a patient at a given occasion. Thereafter, the sum to be paid was calculated from the actual price of the drug(s) prescribed, with a maximum of 1300 SEK ( $\sim \$ U S 125$, based on the exchange rate in 
Autumn 2002). Additional costs were paid by society. The costs for consultation with a physician increased in Sweden in 1997. This may have added to the costs for women who consulted for genital Candida infections and thereby indirectly have affected purchases of prescribed antifungal drugs. After 1999, the cutoff level for a $100 \%$ drug subsidy increased to 1800 SEK for each 12-month period. If a patient concomitantly was prescribed drugs for other conditions, the actual cost for her antifungal therapy may even have become free during a 12month period. Furthermore, as OTC products constitute the bulk of drugs used, subsidies are not likely to have influenced the consumption pattern studied.

\section{Age of sexual debut and sexual practice}

VVC and RVVC are rare conditions before menarche but increase rapidly in rate after the sexual debut ${ }^{3}$. It is therefore likely that the age of sexual debut in an area may influence the consumption of antifungals used to treat these conditions. However, no marked change in the age of sexual debut was seen during the study period.

Sexual practice may also have an impact on the prevalence of VVC/RVVC. In a study of female university students, practice of oral sex was the factor that most markedly differentiated those with and without a history of genital Candida infection $^{13}$. In a study of women with a history of RVVC and with an assumed new attack of the condition, we did not find a correlation between practice of either oral or anal sex and colonization by Candida of genital and extragenital sites ${ }^{14}$.

\section{Concomitant infections and vaginal flora changes}

The very few, i.e. 116, females in Skåne county reported infection by human immunodeficiency virus (HIV) during the entire 1990s, and so concomitant HIV infection could not have had any great influence on total usage of vaginal antifungal products. VVC/RVVC is also a late phenomenon in HIV-infected women (who are not on 'stop medication'). The common switch from C. albicans to non-albicans strains, seen in esophagitis in HIV-infected patients, does not seem to take place in the vagina of HIV-infected women, which would have constituted a therapeutic challenge.

There has been a marked and continuous reduction in the incidence of bacterial vaginosis (BV) in Skåne county over the study period. BV may protect against VVC, because the amines released from anaerobes occurring in high numbers in the vagina in this condition might inhibit germ tube formation in Candida ${ }^{15}$, which seems to be a prerequisite for mycosal invasion by Candida fungi ${ }^{16}$. Extracellular matrix proteins also seem to promote persistance of Candida in the female genital tract. Treatment of BV with metronidazole is followed by VVC in approximately every tenth case, which may favor the assumption of a protective role of anaerobes against the development of VVC/RVVC.

\section{Use of hygiene products and certain clothing}

New trends in behavior may promote VVC and RVVC. For example, use of certain intimate hygiene products and changes in clothing and of the material used in underwear, as well as laundry practices of such clothes ${ }^{3}$, could explain the increase in usage of antifungal drugs at the beginning of the 1990s, but is an unlikely explanation for the decrease later on. Lycra ${ }^{\mathbb{R}}$ and other synthetic materials in underwear, which cannot be washed at temperatures that kill Candida organisms, were introduced onto the Swedish market on a large scale during the study period and could have influenced the rate of RVVC. However, this is not likely to have had any major impact on antifungal drugs sales, as sales of such underwear did not decline during the latter part of the 1990s. The wearing of tight trousers and underwear has been considered to trigger VVC/RVVC, although scientific support for this hypothesis is still lacking ${ }^{3}$. The increased fashion of using string panties became more common during the latter part of the decade, i.e. when the sales of antifungals went down.

\section{Clinical diagnostic dilemma}

Women with RVCC were unskilled to correctly diagnose their disease. Sihro and co-workers ${ }^{17}$ 
reported a high rate of false diagnoses among women assuming themselves to be suffering from RVVC. In addition, these authors found that almost half of such women did not properly use the antifungal drugs that had been prescribed to them by their physician. In the study, using written case scenarios, $34.5 \%$ of women with a previous episode of VVC and only $11 \%$ of these without such an experience $(P<0.001)$ could properly differentiate this condition from others affecting the genital tract, such as pelvic inflammatory disease, trichomoniasis and cystitis. Women with a medical or paramedical profession more often recognized VVC correctly $(83.7 \%)$ than did women without such training. As also indicated in the study by Garcia and associates $^{18}$, syndrome-based management of genital infections is difficult. Pharmacy personnel often failed to recommend the proper therapy for sexually transmitted diseases. An educational intervention program in pharmacies only marginally improved the quality of counseling, and the effect was only temporary ${ }^{18}$. To overcome this problem, integration of courses on infectious gynecological disorders into both basic and postgraduate training of pharmacists should be implemented. However, another recent study ${ }^{19}$ illustrated that counseling at pharmacies could reduce the patient's need for re-consultation with a physician. The usage of OTC products for VVC/RVVC may, as mentioned, also be related to the fact that these diagnoses are difficult to establish ${ }^{4-7}$. Approximately half of all cases with symptoms associated with VVC/ RVVC are Candida culture-negative. However, azole preparations sold for vaginal application often have a positive effect even if Candida cannot be detected, through their additives of anti-pruritus and anti-inflammatory effects.

One threat to optimal healthcare posed by uncontrolled access to antifungal OTC products could be reduction in the early detection of carriers of sexually transmitted infectious agents and of patients with genital cancer or precancerous conditions, wrongly assumed to be RVVC. Symptoms such as itching and discharge, which are common in VVC and RVVC, may also occur in those suffering from such other conditions. For example, itching is one of the most common complaints in chlamydia infections. It is of note that genital chlamydial infections decreased over the study period in the county and therefore did not mirror the trend of azole products usage.

\section{Concomitant drug use}

Contraceptives use, i.e. of estrogen- and gestagens-containing products, may have influenced the prevalence of VVC/RVVC and thereby the sales of antifungals. The oral contraceptives market did increase by $20 \%$ in Skåne during the 1990s. However, the constant addition of new contraceptives onto the market during this period makes it difficult to establish the impact of each such drug on the epidemiology on genital Candida infections. Thus sales of oral contraceptive drugs did not mirror those of antifungal drugs. As already mentioned elsewhere ${ }^{8}$, neither did the prescription of hormone replacement therapy in the county during the 1990s change sales volumes in the manner found for the antifungal drugs studied.

Some drugs are known to be "non-antibiotic antibiotics', i.e. to have an antibacterial effect apart from that of their main action ${ }^{20}$. However, their effect on fungi is still unknown. For example, non-steroidal anti-inflammatory drugs, like ibuprofen, not only have an antifungal effect but also act synergistically with fluconazole ${ }^{21}$.

The sales of antibiotics in Sweden increased up to the middle of the 1990s and decreased thereafter $^{22}$ (Figure 4). In 1999, the consumption level was equal to that of 1983 . Thus, the trend roughly paralleled the usage of antifungal drugs seen in Skåne over the study period. Therefore, antibiotics use could be one factor that may have had at least a marginal impact on sales of drugs for VVC/RVVC. Intensive therapy with some antibiotics may result in overgrowth of Candida in the vagina. Antifungal drugs are often prescribed by some gynecologists when prescribing a broadspectrum antibiotic to a woman to counteract the risk that she will develop VVC.

Women with RVVC were significantly more likely to suffer clinical depression, to be less satisfied with life, to have poor self-esteem and to perceive their lives as more stressful than were controls $^{23}$. Whether the massive use of antide- 


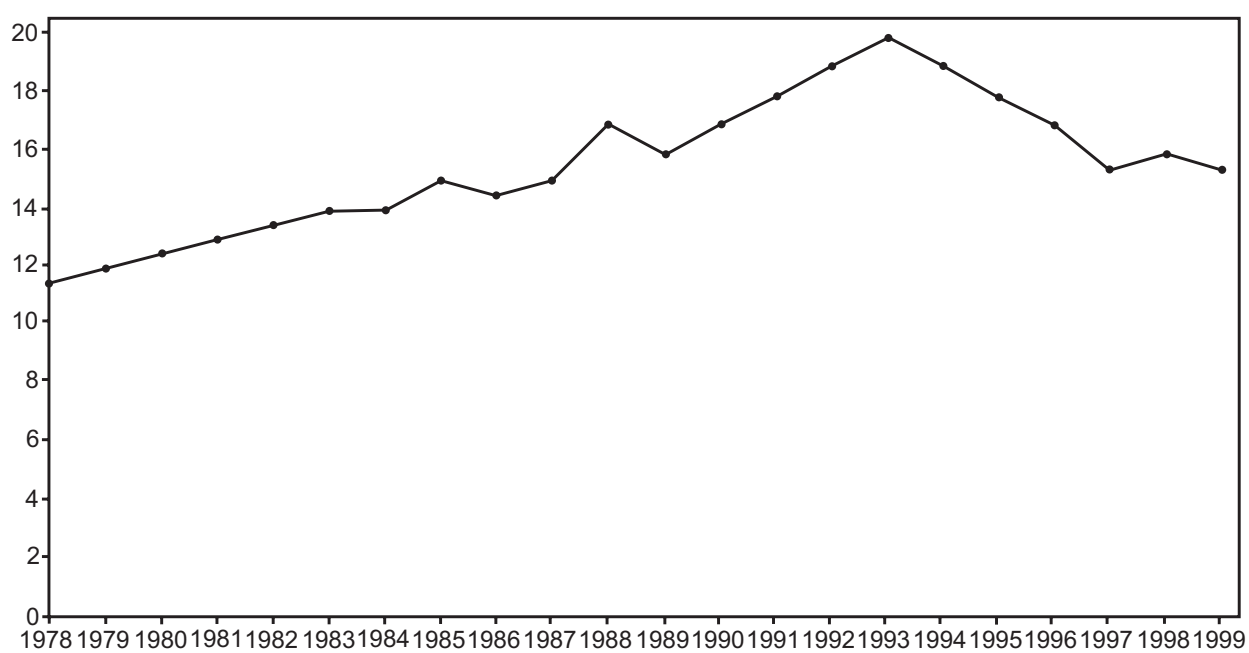

Figure 4 Consumption of antibiotics in Sweden during 1982-199822. Daily defined dose per I,000 inhabitants

pressive drugs can indirectly influence the sale of antifungals remains, however, to be proved.

\section{CONCLUSIONS}

Despite analyzing a large number of factors in an attempt to explain why there were such marked changes in the usage of antifungal drugs for therapy of VVC/RVVC in Skåne during the 1990s, it was not possible to identify any single factor or even combination of factors that could be responsible. Neither is it likely that the usage pattern mirrored a change in the epidemiology of genital Candida infections; conditions not considered to be contagious (not representing sexually transmitted conditions). The common usage of OTC products aimed for VVC/RVVC therapy may be an overconsumption related to the fact that these diagnoses are difficult to establish. Approximately half of all such assumed cases are negative in laboratory tests for Candida.

\section{REFERENCES}

1. Eckert LO, Hawes SW, Stevens CE, et al. Vulvovaginal candidiasis: clinical manifestations, risk factors, management algorithm. Obstet Gynecol 1998;92:757-65

2. Sobel JD, Faro S, Force RW, et al. Vulvovaginal candidiasis: epidemiologic, diagnosis and therapeutic considerations. Am J Obstet Gynecol 1998;178:203-11

3. Mårdh P-A, Rodrigues AG, Genç M, et al. Facts and myths on recurrent vulvovaginal candidosis epidemiology, clinical manifestations, diagnosis, pathogenesis and therapy. Int $J$ STD/AIDS 2002;13:522-39

4. Schaaf VM, Perez-Stable EJ, Borchardt K. The limited value of symptoms and signs in the diagnosis of vaginal infections. Arch Intern Med 1990;150:1929-33
5. Mårdh P-A, Tchoudomirova E, Elshibly S, Hellberg D. Symptoms and signs in single and mixed genital infections in attendees of family planning and youth clinics. Int J Gynaecol Obstet 1998; 63:145-52

6. Ledger WJ. Current problems in the diagnosis and treatment of Candida vaginitis. Ital J Obstet Gynecol 1999;11:25-9

7. Mårdh P-A, Novikova N. RVVC - a puzzling condition. In Kohl PK, Jod SJ, eds. Proceedings of the International Congress on Sexually Transmitted Infections (ISSTDR/IUSTI), Berlin, 2001. Bologna: Monduzzi Editore, 2001:147-52 
8. Mårdh P-A, Wågström J, Landgren M, Holmén J. Usage of antifungal drugs for therapy of genital Candida infections, purchased as over the counter products or by prescription: 1. Analyses of a unique database. Infect Dis Obstet Gynecol 2004;12:000-00

9. ACS, Apotekets Centrala Statistik [database]. Apoteket AB, Sweden

10. Brown D Jr, Binder GL, Gardner HL, Wells J. Comparison of econazole and clotrimazole in the treatment of vulvovaginal candidiasis. Obstet Gynecol 1980;56:121-3

11. Sobel JD, Muller G. Ketoconazole prophylaxis in experimental vaginal candidiasis. Antimicrob Agents Chemother 1984;25:281-2

12. Calderon-Marquez JJ. Itraconazole in the treatment of vaginal candidosis and the effect treatment of the sexual partner. Rev Infect Dis 1987;9:S143-5

13. Geiger AM, Foxman B. Risk factors in vulvovaginal candidiasis: a case-control study among university students. Epidemiology 1996;7:182-7

14. Mårdh P-A, Novikova N, Stukalova E. Colonisation of extragenital sites by Candida in cases of recurrent vulvovaginal candidosis. $\mathrm{Br} J$ Obstet Gynaecol 2003;110:934-7

15. Rodrigues AG, Mårdh P-A, Pina Vaz C, et al. Is lack of concurrence of bacterial vaginosis and candidosis explained by presence of bacterial amines? Am J Obstet Gynecol 1999;181:367-70

RECEIVED 02-24-03; ACCEPTED 09-24-03
16. Rodrigues A, Pina-Vaz C, Mårdh P-A, et al. In vitro effect of fibrinogen on Candida albicans germ tube formation. APMIS 1999;107:1020-2

17. Sihro S, Ahonen R, Mikander H, Hemminki E. Self-medication with vaginal antifungal drugs: physicians' experiences and women's utilization. Fam Pract 2000;17:145-9

18. Garcia PJ, Gotuzzo E, Hughes JP, Holmes KK. Syndrome management of STDs in pharmacies: evaluation and randomized intervention trial. Sex Transm Infect 1998;74:153-8

19. Whittington Z, Cantrill J, Hassell K, et al. Community pharmacy management of minor conditions - the 'care of the chemist' scheme. Pharm J 2001;266:425-8

20. Cederlund H, Mårdh P-A. Antimicrobial activities of non-antibiotic drugs. $J$ Antimicrob Chemother 1993;32:355-65

21. Pina-Vaz C, Sansonetty F, Martinez-de-Oliveira $\mathrm{J}$, et al. Antifungal effect of ibuprofen alone and in combination with fluconazole against Candida species. J Med Microbiol 2000;49:831-40

22. Apoteket AB. Svensk Läkemedellsstatistik-99 [Swedish Medical Drug Statistics]. Sweden: Apoteket AB, 1999

23. Miller G, Irving D, Robinson A, et al. Psychological factors associated with recurrent vaginal candidiasis: a preliminary study. Sex Transm Infect 1998;74:334-8 


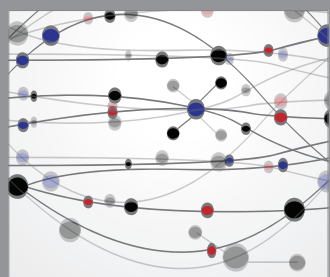

The Scientific World Journal
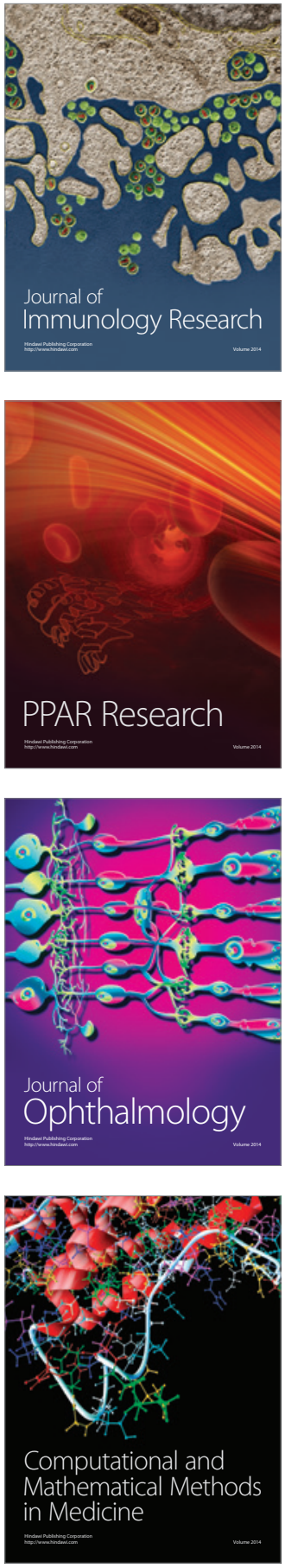

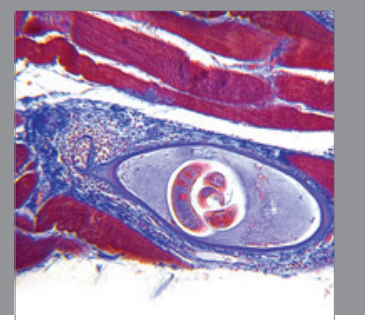

Gastroenterology

Research and Practice
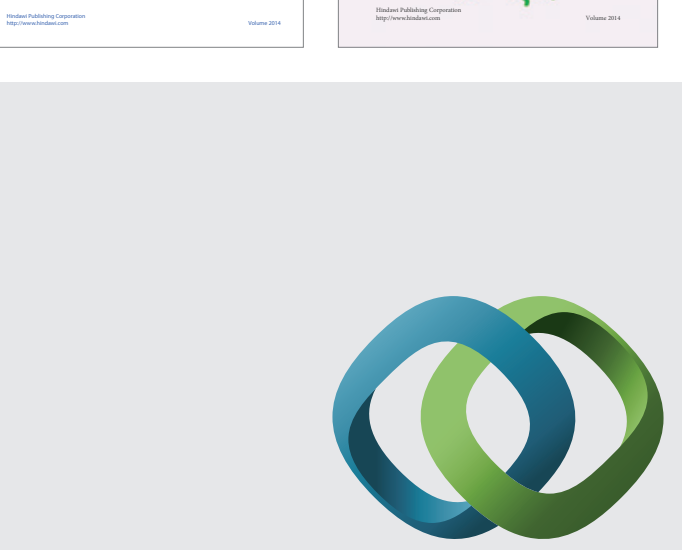

\section{Hindawi}

Submit your manuscripts at

http://www.hindawi.com
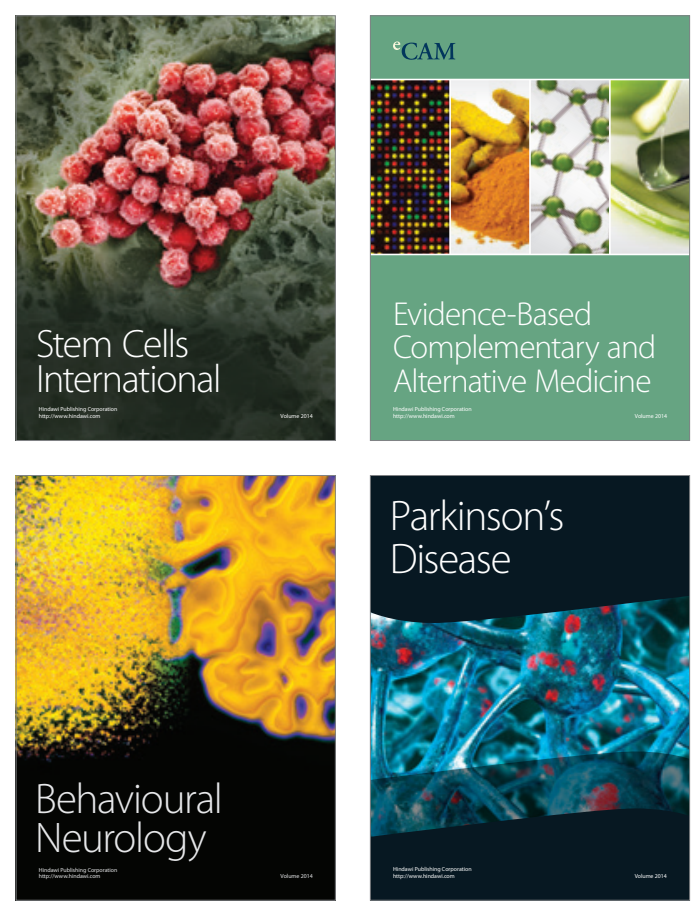

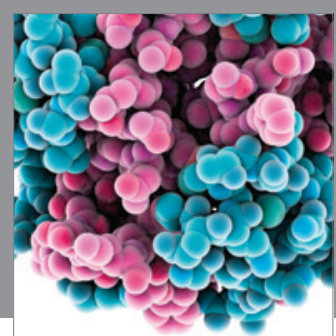

Journal of
Diabetes Research

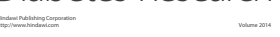

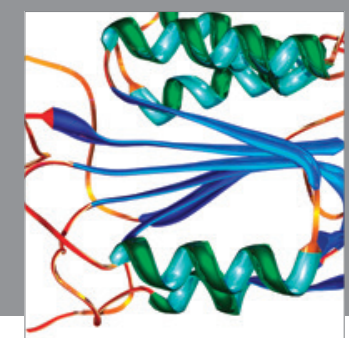

Disease Markers
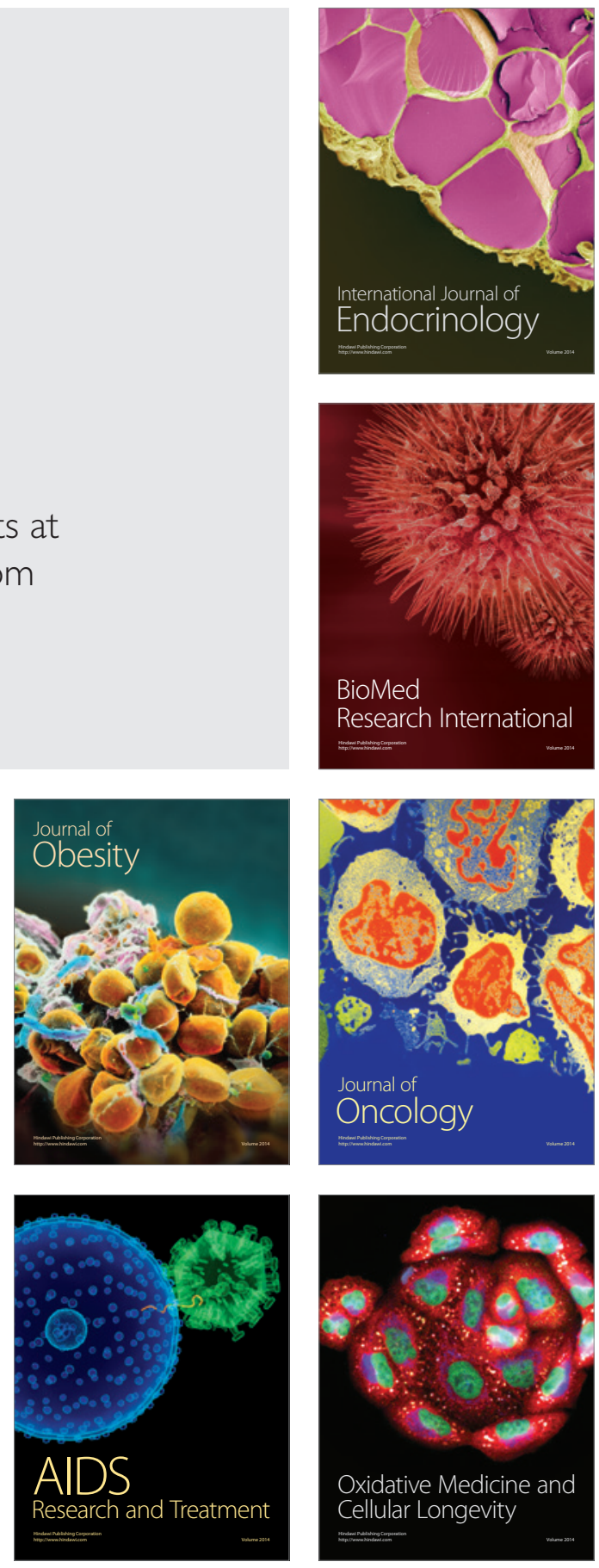